\title{
Influence of indacaterol on daily physical activity in patients with untreated chronic obstructive pulmonary disease
}

This article was published in the following Dove Press journal:

International Journal of COPD

27 February 2015

Number of times this article has been viewed

\author{
Yu Nishijima',* \\ Seigo Minami ${ }^{1, *}$ \\ Suguru Yamamoto' \\ Yoshitaka Ogata' \\ Taro Koba ${ }^{1,2}$ \\ Shinji Futami ${ }^{1}$ \\ Kiyoshi Komuta' \\ 'Department of Respiratory \\ Medicine, Osaka Police Hospital, \\ Tennoji-ku, Osaka, Japan; ${ }^{2}$ Department \\ of Internal Medicine, National \\ Hospital Organization, Kinki-Chuo \\ Chest Medical Center, Kita-ku, Sakai, \\ Osaka, Japan \\ *These authors contributed equally \\ to this work
}

Correspondence: Seigo Minami

Department of Respiratory Medicine, Osaka Police Hospital, I0-3I Kitayamacho, Tennoji-ku, Osaka 543-0035, Japan

$\mathrm{Tel}+8$ I 6 677। 605।

Fax +8I 6 677। 2838

Email seigominami@oph.gr.jp
Background: Indacaterol, a once-daily, long-acting $\beta_{2}$-agonist, may improve not only respiratory function, dyspnea symptoms, and quality of life, but also physical activity for patients with chronic obstructive pulmonary disease (COPD). This study aimed to evaluate the effect of 12-week indacaterol therapy on daytime physical activity in patients with untreated COPD.

Methods: The subjects were stable and untreated COPD outpatients with a percent predicted forced expiratory volume in 1 second $\left(\% \mathrm{FEV}_{1}\right)$ below $80 \%$. Baseline assessments included clinical assessment, respiratory function testing, arterial blood gas analysis, the COPD assessment test (CAT ${ }^{\mathrm{TM}}$ ), and the Medical Outcomes Study 36-Item Short-Form Health Survey, Japanese version $2\left(\mathrm{SF}-36 \mathrm{v} 2^{\circledR}\right)$. Patients underwent monitoring by uniaxial accelerometer before and after 12 weeks once-daily inhalation of indacaterol $150 \mu \mathrm{g} / \mathrm{day}$.

Results: Eighteen patients were evaluable. Patient characteristics included a mean age of 74.2 years, and three patients were current smokers. Indacaterol improved mean ( \pm standard deviation $[\mathrm{SD}]) \% \mathrm{FEV}_{1}$ from $55.2 \%( \pm 17.9 \%)$ to $61.0 \%( \pm 17.3 \%)(P=0.003)$, CAT scores from $16.4( \pm 10.2)$ points to $12.4( \pm 8.2)$ points $(P=0.04)$, some scales of the SF-36v2 (physical component summary, $41.6 \pm 9.7$ points to $45.1 \pm 7.9$ points, $P=0.03$ ), and number of daily steps $(3,311.5 \pm 2,103.3$ steps/day to $3,841.8 \pm 2,096.8$ steps/day, $P=0.02)$, but did not affect daily energy expenditure $(85.0 \pm 77.2 \mathrm{kcal}$ change to $90.9 \pm 56.8 \mathrm{kcal}, P=0.29)$ or exercise duration of an intensity of level 1 or more ( $36.4 \pm 23.9$ minutes increase to $40.8 \pm 21.6$ minutes, $P=0.12$ ). Conclusion: Twelve weeks of indacaterol improved respiratory function and quality of life, but did not significantly affect physical activity in patients with moderate-to-severe COPD.

Keywords: indacaterol, long-acting $\beta_{2}$-agonist, chronic obstructive pulmonary disease, physical activity, uniaxial accelerometer

\section{Introduction}

Chronic obstructive pulmonary disease (COPD) is caused by a chronic inflammatory process of the airways, due mainly to excessive cigarette smoking. Mortality in COPD is increasing and is predicted to be the third highest cause of death by $2020 .{ }^{1}$

Exercise capacity evaluated by the peak oxygen uptake ${ }^{2}$ and 6-minute walk distance ${ }^{3}$ predicts survival in patients with COPD. Physical activity in daily life is highly correlated with functional exercise capacity. ${ }^{4}$ Patients with COPD are more inactive in daily life than healthy subjects. ${ }^{4,5}$ Monitoring of physical activity may be the strongest predictor of all-cause mortality in patients with COPD. ${ }^{6}$

Pharmacologic therapy is necessary for reducing symptoms and frequency of exacerbation due to COPD, and improving health status and exercise tolerance. ${ }^{7}$ The inhaled bronchodilator is currently a main player in the pharmacologic management of COPD. There are two types of inhaled long-acting bronchodilators that are recommended for 
long-term maintenance therapy in patients with moderate-tosevere COPD: long-acting muscarinic antagonists (LAMA) and long-acting $\beta_{2}$-agonists (LABA). Indacaterol (Onbrez ${ }^{\circledR}$ inhalation powder; Novartis International AG, Basel, Switzerland), a once-daily LABA, maintained significant improvement at 12 weeks in forced expiratory volume in one second $\left(\mathrm{FEV}_{1}\right)$ assessed by pulmonary function tests, dyspnea symptoms, and quality of life (QOL) in patients with moderate-tosevere COPD, when compared with placebo, ${ }^{8-10}$ salmeterol, ${ }^{11}$ and tiotropium. ${ }^{8,12}$ Recent studies indicated that 2-3 weeks of indacaterol reduced lung hyperinflation and then improved exercise endurance. ${ }^{13-15}$ Additionally, 3-4 weeks of indacaterol also improved daily physical activity. ${ }^{15,16}$ This study aimed to evaluate the effect of 12-week indacaterol therapy on daily daytime physical activity in untreated patients with COPD.

\section{Materials and methods Subjects}

Patients were recruited from the outpatient clinic in the Department of Respiratory Medicine at Osaka Police Hospital. The inclusion criteria were: 1) 40 years of age or older; 2) a history of smoking or excessive environmental tobacco smoke; 3) clinically stable COPD according to the Global Initiative on Obstructive Lung Disease (GOLD) guidelines; ${ }^{17} 4$ ) a predicted $\left.\mathrm{FEV}_{1}\left(\% \mathrm{FEV}_{1}\right)<80 \% ; 5\right)$ no treatment with LABA or LAMA for more than 4 weeks before enrollment; 6) ability to walk independently or with a cane; 7) sufficient cognitive function to follow instructions for using the accelerometer; and 8) written informed consent. The exclusion criteria were: 1) pregnancy, lactation, suspicion of being pregnant; 2) an exacerbation within 1 month before enrollment; 3) other significant respiratory diseases or medical problems that precluded ambulatory activities at home; 4) clinically severe bronchial asthma; 5) patient undergoing pulmonary rehabilitation; or 6) a history of hypersensitivity reaction against any LABA.

\section{Experimental design}

This was an open-label clinical trial with no randomization and no placebo group. To record physical activity, the patients carried a uniaxial accelerometer, Lifecorder ${ }^{\circledR}$ Ex 4-second version (Suzuken Corporation, Nagoya, Japan), which analyzed the movement intensity level every 4 seconds on a scale of 0.5 (minimal intensity of movement) to 9 (maximal intensity of movement) on the basis of the magnitude and frequency of accelerations. The activity intensity level measured by Lifecorder Ex is highly related with metabolic equivalents (METs). ${ }^{18}$ Unlike other studies that used Lifecorder Ex, we purposely did not convert our raw data of activity intensity level into METs. This device was fixed to patient belts or waistbands for more than 1 week before and 12 weeks after indacaterol therapy. Patients inhaled indacaterol $150 \mu \mathrm{g} /$ day once daily during 12 weeks of the treatment. Thereafter, during the post-treatment accelerometer monitoring period, patients continued indacaterol inhalation. Patients were instructed by nurses on how to correctly use the inhalator device (Breezhaler ${ }^{\circledR}$ device; Novartis International AG) before indacaterol therapy, and by physicians on how to set up the device every day from 9 am until 5 pm, before each monitoring period. After each monitoring period, the patients returned the accelerometers to the investigators. Thereafter, the stored data were uploaded to a computer for analysis. Monitoring time was based on the study by Sugino et al which used a triaxial accelerometer, Actimarker $^{\circledR}$, for 7 hours from 10 am to $5 \mathrm{pm}$ in patients with COPD and concluded that the data from at least three non-rainy weekdays were reliable. ${ }^{19}$ Monitoring data on rainy days, on hospital visit days, and outside of defined hours, before 9 am or after 5 pm, and in patients who had insufficient accelerometer data (less than 3 days) were excluded from analysis.

Before and after indacaterol therapy, all patients underwent spirometry, assessment of the modified Medical Research Council (mMRC) dyspnea scale score, ${ }^{20}$ the Japanese version of the COPD assessment test (CAT ${ }^{\mathrm{TM}}$ ), ${ }^{21,22}$ and the Medical Outcomes Study 36-Item Short-Form Health Survey Japanese version $2\left(\mathrm{SF}-36 \mathrm{v} 2^{\circledR}\right){ }^{23,24}$ Spirometry was assessed by an autospirometer (Autospirometer System 7; Minato Medical Science, Osaka, Japan) according to the American Thoracic Society guidelines. ${ }^{25}$ Before indacaterol therapy, all patients also received arterial blood gas analysis. Arterial blood samples from the radial artery under breathing room air were immediately measured by a blood gas analyzer (RAPIDPoint ${ }^{\mathrm{TM}} 405$ Arterial Blood Gas Analyzer; Siemens Healthcare Diagnostics Inc, Tarrytown, NY, USA).

The primary outcome was duration of light or more exercise, defined as exercise with an intensity of level 1 or more monitored by Lifecorder. The secondary outcomes were QOL questionnaire results and respiratory function. Based on the previous studies by Pitta et $\mathrm{l}^{4}$ and Hataji et a ${ }^{16}$ the physical activity time with an intensity of $\geq$ level 1 was estimated to increase from 144 minutes (30\% of all monitoring duration in a day, 8 hours) to 201 minutes (42\%). For a standard deviation of 72 minutes (15\%), with a one-sided alpha of $5 \%$ and a power of $90 \%$, we estimated that 15 evaluable subjects would be needed. Given the possibility of incomplete data in some patients, we estimated that 22 subjects would be needed for this study.

The ethics committee of the Osaka Police Hospital approved the study. All patients provided written informed consent for inclusion in the study. 


\section{Data analysis}

The values for normally distributed continuous variables, discrete variables, and categorical variables are expressed as the mean \pm standard deviation (SD), median (range), and frequency. Comparisons before and after indacaterol therapy were performed using the paired $t$-test for normally distributed continuous variables, or the nonparametric Wilcoxon rank test for discrete variables. A one-sided $P$-value of $<0.05$ was considered statistically significant. Statistical analyses were performed using the Statcel statistical package (Statcel3; OMS Inc, Tokorozawa, Japan).

\section{Results}

From February 2013 to May 2014, 23 patients were enrolled. Five patients were excluded from the analyses because of unexpectedly exacerbated comorbid orthopedic disease requiring hospitalization, new malignancy, mild but persistent coarse voice resulting in the patient's rejection, unavailability during the protocol treatment, and insufficient monitoring data. Thus, 18 patients were evaluable for analyses. The baseline characteristics are shown in Table 1. Among 15 ex-smokers, exposure to excessive smoke was possibly a main cause of COPD in two patients (one man and one woman). None were on active smoking cessation pharmacotherapy. No participants used inhaled corticosteroids.

Despite the increased mean number of steps $(3,311.5 \pm$ $2,103.3$ to $3,841.8 \pm 2,096.8$ steps/day, $P=0.02$ ), indacaterol did not improve energy expenditure $(85.0 \pm 77.2 \mathrm{kcal} /$ day changed

Table I Baseline characteristics of analyzed patients $(\mathrm{N}=18)$

\begin{tabular}{|c|c|}
\hline Characteristics & Baseline data \\
\hline \multicolumn{2}{|l|}{ Age (years) } \\
\hline Mean \pm SD & $74.2 \pm 6.5$ \\
\hline \multicolumn{2}{|l|}{$\operatorname{Sex}(N)$} \\
\hline Male/female & $17 / 1$ \\
\hline \multicolumn{2}{|l|}{ Body mass index $\left(\mathrm{kg} / \mathrm{m}^{2}\right)$} \\
\hline Mean \pm SD & $21.0 \pm 2.4$ \\
\hline \multicolumn{2}{|l|}{ Smoking status (N) } \\
\hline CS/ex & $3 / 15$ \\
\hline \multicolumn{2}{|l|}{ Smoking (packs/year)a } \\
\hline Mean \pm SD & $37.6 \pm 22.3$ \\
\hline \multicolumn{2}{|l|}{ Working status (N) } \\
\hline Worker/retired/housewife & $4 / 13 / 1$ \\
\hline \multicolumn{2}{|l|}{ GOLD stage $(\mathrm{N})$} \\
\hline I/II/III/IV & $0 / 11 / 4 / 3$ \\
\hline \multicolumn{2}{|l|}{$\mathrm{PaO}_{2}(\mathrm{mmHg})$} \\
\hline Mean \pm SD & $79.8 \pm 10.4$ \\
\hline \multicolumn{2}{|l|}{$\mathrm{PaCO}_{2}(\mathrm{mmHg})$} \\
\hline Mean \pm SD & $39.3 \pm 3.6$ \\
\hline
\end{tabular}

Note: ${ }^{a}$ One ex-smoker was excluded because of unknown smoking history. Abbreviations: CS, current smoker; ex, ex-smoker; GOLD, Global Initiative for Chronic Obstructive Lung Disease; SD, standard deviation. to $90.9 \pm 56.8 \mathrm{kcal} / \mathrm{day}, P=0.29)$, exercise duration of light or more exercise ( $36.4 \pm 23.9$ minutes/ 8 hours/day to $40.8 \pm 21.6$ minutes/ 8 hours/day, $P=0.12$ ), or exercise duration of moderate or more exercise $(9.5 \pm 15.2$ minutes/ 8 hours/day to $9.2 \pm 10.0$ minutes/ 8 hours/day, $P=0.55$ ) (Table 2 ).

Indacaterol significantly improved mean $\mathrm{FEV}_{1}(1.46 \pm 0.56 \mathrm{~L}$ increased to $1.58 \pm 0.54 \mathrm{~L}, P=0.002)$ and $\% \mathrm{FEV}_{1}(55.2 \% \pm 17.9 \%$ increased to $61.0 \% \pm 17.3 \%, P=0.003)$, CAT scores $(16.4 \pm 10.2$ points at baseline decreased to $12.4 \pm 8.2$ points, $P=0.04$ ). Among eight scales and three component summaries of the SF-36v2, general health scale scores $(53.0 \pm 19.8$ points increased to $63.1 \pm 21.3$ points, $P=0.02$ ), role emotional scale scores ( $72.5 \pm 31.0$ points rose to $83.3 \pm 24.7$ points, $P=0.049$ ), and physical component summary scores $(41.6 \pm 9.7$ points at baseline to $45.1 \pm 7.9$ points at the end of the study, $P=0.03$ ), were significantly improved (Table 3 ).

\section{Discussion}

This was the third study, after the studies by Hataji et a $\mathrm{l}^{16}$ and Watz et $\mathrm{al}^{15}$ that investigated whether indacaterol improved daily physical activity in patients with COPD. However, the results of our study contradicted those of the previous two studies.

The most important finding is that 12 weeks of indacaterol did not result in a significant improvement in physical activity time in patients with moderate or severe COPD. This result was contrary to those of the previous two studies, which demonstrated that indacaterol significantly improved physical activity in patients with COPD. In a Japanese, nonrandomized, and open-label study by Hataji et al Lifecorder showed a significant increase in physical activity within 4 weeks of the initiation of indacaterol treatment. ${ }^{16}$ Similarly, in a German, randomized, placebo-controlled, crossover study by Watz et al 3 weeks of indacaterol significantly improved physical activity as measured by the SenseWear Armband $^{\circledR}$, an exploratory endpoint. ${ }^{15}$ The discrepancy with our results might be a result of differences in monitoring time and the patient populations. The monitoring times were from the time of awakening to bedtime for 8 consecutive weeks before and after indacaterol introduction in the previous Japanese study, ${ }^{16}$ for more than 22 hours per day during the last 1 week of a 21-day treatment cycle in the latest German study. ${ }^{15}$ On the other hand, we monitored for 8 hours in the daytime, $9.00 \mathrm{am}-5.00 \mathrm{pm}$, and more than 3 non-rainy days before indacaterol introduction and after 12-week treatment. Although indacaterol improved exercise endurance and hyperinflation as early as 3 weeks after treatment, ${ }^{14}$ this drug also maintained an improvement in pulmonary function and QOL for 12 weeks after treatment. ${ }^{8,11,12}$ We were also 
Table 2 Changes in daily physical activity $(\mathrm{N}=18)$

\begin{tabular}{|c|c|c|c|}
\hline Parameter & $\begin{array}{l}\text { Before indacaterol } \\
\text { introduction }\end{array}$ & $\begin{array}{l}\text { After } 12 \text {-weeks of } \\
\text { indacaterol treatment }\end{array}$ & $P$-value \\
\hline Days of analysis (days) & $13.3 \pm 6.3$ & $19.3 \pm 7.6$ & $0.0 \mathrm{I}^{\mathrm{a}}$ \\
\hline Number of steps (steps/day) & $3,3 \mid 1.5 \pm 2,103.3$ & $3,841.8 \pm 2,096.8$ & $0.02^{\mathrm{a}}$ \\
\hline Energy expenditure (kilocalories/day) & $85.0 \pm 77.2$ & $90.9 \pm 56.8$ & $0.29^{\mathrm{a}}$ \\
\hline \multicolumn{4}{|l|}{ Duration of exercise (minutes/day) } \\
\hline Intensity level I & $6.2 \pm 6.6$ & $6.6 \pm 3.6$ & $0.8 I^{\mathrm{a}}$ \\
\hline Intensity level 2 & $13.6 \pm 7.8$ & $16.5 \pm 9.1$ & $0.99^{\mathrm{a}}$ \\
\hline Intensity level 3 & $7.0 \pm 5.0$ & $8.4 \pm 5.9$ & $0.93^{\mathrm{a}}$ \\
\hline Intensity level 4 & $5.5 \pm 7.5$ & $6.1 \pm 5.8$ & $0.66^{\mathrm{a}}$ \\
\hline Intensity level 5 & $3.2 \pm 6.6$ & $2.1 \pm 3.7$ & $0.13^{\mathrm{a}}$ \\
\hline Intensity level 6 & $0.8 \pm 1.7$ & $0.9 \pm 1.6$ & $0.73^{\mathrm{a}}$ \\
\hline$\geq$ intensity level 7 & $0.1 \pm 0.2$ & $0.2 \pm 0.2$ & $0.93^{\mathrm{a}}$ \\
\hline $\begin{array}{l}\text { Duration of light or more exercise } \\
\text { (intensity level I or more) (minutes/day) }\end{array}$ & $36.4 \pm 23.9$ & $40.8 \pm 21.6$ & $0.12^{\mathrm{a}}$ \\
\hline $\begin{array}{l}\text { Duration of moderate or more exercise } \\
\text { (intensity, level } 4 \text { or more) (minutes/day) }\end{array}$ & $9.5 \pm 15.2$ & $9.2 \pm 10.0$ & $0.55^{\mathrm{a}}$ \\
\hline
\end{tabular}

Notes: aOne-sided, paired $t$-test. Data shown is mean \pm standard deviation.

concerned that every day, long-time monitoring might be affected by day-to-day variability such as changes of clothes, bathing, time of awakening and bedtime. As for patient population, patients were of an older $(74.2 \pm 6.5$ years age in our study vs $69.74 \pm 1.6$ years in the Hataji et al study ${ }^{16}$ vs $61.4 \pm 8.9$ years in the Watz et al study ${ }^{15}$ ), had more severe pulmonary dysfunction $\left(\mathrm{FEV}_{1} ; 1.46 \pm 0.56 \mathrm{~L}\right.$ vs $1.71 \pm 0.13 \mathrm{~L}^{16}$ vs $1.90 \pm 0.51 \mathrm{~L}^{15} \% \mathrm{FEV}_{1}, 55.2 \% \pm 17.9 \%$ vs $64.5 \% \pm 4.3 \%{ }^{16}$ vs $64.02 \% \pm 9.38 \%,{ }^{15}$ respectively), and worse QOL (CAT scores, $16.4 \pm 10.2$ points in our study vs $11.6 \pm 1.5$ points in the Hataji et al study ${ }^{16}$ ). The previous Japanese study included $61 \%$ of patients treated with tiotropium and $26 \%$ of patients with a mild stage of $\% \mathrm{FEV}_{1} \geq 80 \%,{ }^{16}$ the latest German study recruited only untreated patients with a moderate stage of $50 \% \leq \mathrm{FEV}_{1} \%<80 \%,{ }^{15}$ while our study recruited untreated patients with moderate or severe stage and included 39\%

Table 3 Changes in pulmonary functions and QOL questionnaires $(\mathrm{N}=18)$

\begin{tabular}{|c|c|c|c|c|}
\hline Parameter & $\mathbf{N}$ & $\begin{array}{l}\text { Before indacaterol } \\
\text { introduction }\end{array}$ & $\begin{array}{l}\text { After I2-weeks of } \\
\text { indacaterol treatment }\end{array}$ & $P$-value \\
\hline \multicolumn{5}{|l|}{ Pulmonary functions } \\
\hline $\mathrm{FEV}_{1}(\mathrm{~L})$ & 18 & $1.46 \pm 0.56$ & $1.58 \pm 0.54$ & $0.002^{\mathrm{a}}$ \\
\hline$\% F E V_{1}(\%)$ & 18 & $55.2 \pm 17.9$ & $61.0 \pm 17.3$ & $0.003^{\mathrm{a}}$ \\
\hline $\mathrm{FVC} \mathrm{(L)}$ & 18 & $2.33 \pm 0.72$ & $2.49 \pm 0.63$ & $0.06^{\mathrm{a}}$ \\
\hline $\mathrm{mMRC}$ & 18 & $1.3 \pm 1.1$ & $1.2 \pm 1.0$ & $0.79^{b}$ \\
\hline $\mathrm{CAT}^{\mathrm{TM}}$ & 17 & $16.4 \pm 10.2$ & $12.4 \pm 8.2$ & $0.04^{a}$ \\
\hline \multicolumn{5}{|l|}{ SF-36v2 ${ }^{\circledR}$} \\
\hline Physical function & 17 & $77.8 \pm 16.0$ & $80.6 \pm 17.0$ & $0.26^{\mathrm{a}}$ \\
\hline Role physical & 17 & $64.3 \pm 28.7$ & $74.6 \pm 26.5$ & $0.06^{\mathrm{a}}$ \\
\hline Body pain & 17 & $74.5 \pm 25.4$ & $81.5 \pm 23.3$ & $0.06^{\mathrm{a}}$ \\
\hline General health & 18 & $53.0 \pm 19.8$ & $63.1 \pm 21.3$ & $0.02^{\mathrm{a}}$ \\
\hline Vitality & 17 & $62.5 \pm 25.1$ & $65.4 \pm 23.7$ & $0.32^{\mathrm{a}}$ \\
\hline Social function & 17 & $74.3 \pm 30.8$ & $82.4 \pm 28.0$ & $0.15^{\mathrm{a}}$ \\
\hline Role emotional & 17 & $72.5 \pm 31.0$ & $83.3 \pm 24.7$ & $0.049^{a}$ \\
\hline Mental health & 17 & $69.1 \pm 25.8$ & $70.9 \pm 18.8$ & $0.38^{\mathrm{a}}$ \\
\hline Physical component summary & 16 & $41.6 \pm 9.7$ & $45.1 \pm 7.9$ & $0.03^{\mathrm{a}}$ \\
\hline Mental component summary & 16 & $54.7 \pm 12.8$ & $54.7 \pm 11.2$ & $0.50^{\mathrm{a}}$ \\
\hline Role/social component summary & 16 & $41.1 \pm 16.6$ & $43.8 \pm 15.8$ & $0.19^{a}$ \\
\hline
\end{tabular}

Notes: ${ }^{a}$ One-sided, paired $t$-test; ${ }^{b}$ one-sided Wilcoxon signed rank test. Data shown is mean \pm standard deviation.

Abbreviations: CAT ${ }^{\mathrm{TM}}$, the Japanese version of the chronic obstructive pulmonary disease (COPD) assessment test; FEV FVC, forced vital capacity; mMRC, modified Medical Research Council dyspnea scale score; QOL, quality-of-life; SF-36v2 ${ }^{\circledR}$, Medical Outcomes Study $36-$ Item Short-Form Health Survey, Japanese version 2. 
of patients with $\% \mathrm{FEV}_{1}<50 \%$. Consequently, despite the indirect comparison, our patients might be more inactive even after indacaterol therapy than those in previous studies (total number of steps: $3,841.8 \pm 2,096.8$ steps/ 8 hours/ day in our study vs $7,857.7 \pm 847.9$ /waking hours/day in the Hataji et al study ${ }^{16}$ vs $7,341 / \geq 22$ hours/day in the Watz et al study, ${ }^{15}$ and energy expenditure: $90.9 \pm 56.8 \mathrm{kcal} / 8$ hours/day in our study vs $193.6 \pm 23.4 \mathrm{kcal} /$ waking hours/day in the Hataji et al study ${ }^{16}$ ).

There were several limitations to our study. First, our study was of small sample size, open-label, non-randomized, and non-placebo controlled. Some patients might have been psychologically encouraged to become more active 12 weeks after indacaterol. Second, we did not distinguish between workers and retired patients in analyses of physical activity, because we did not obtain detailed working schedules and activities from the four current workers. Sunday is reported to be different in activity duration from other days, and was the last day entered in the analysis, ${ }^{26}$ while retired patients with COPD spend a similar time in physical activities on weekend days compared with weekdays. ${ }^{27}$ Nowadays, irregular working shifts may also make it difficult to monitor the physical activities of workers with COPD.

Based on this study, our next clinical study will evaluate the effect of a LAMA, glycopyrronium, on physical activity in untreated patients with moderate-to-severe COPD (clinical trial number UMIN000014303).

\section{Conclusion}

In conclusion, we demonstrated that 12 weeks of indacaterol improved respiratory functions and QOL, but did not show an effect on physical activity in patients with moderate-tosevere COPD.

\section{Disclosure}

The authors report no conflicts of interest in this work.

\section{References}

1. Murray CJ, Lopez AD. Alternative projections of mortality and disability by cause 1990-2020: Global Burden of Disease Study. Lancet. 1997;349(9064):1498-1504.

2. Oga T, Nishimura K, Tsukino M, Sato S, Hajiro T. Analysis of the factors related to mortality in chronic obstructive pulmonary disease: role of exercise capacity and health status. Am J Respir Crit Care Med. 2003;167(4):544-549

3. Pinto-Plata VM, Cote C, Cabral H, Taylor J, Celli BR. The 6-min walk distance: change over time and value as a predictor of survival in severe COPD. Eur Respir J. 2004;23(1):28-33.

4. Pitta F, Troosters T, Spruit MA, Probst VS, Decramer M, Gosselink R. Characteristics of physical activities in daily life in chronic obstructive pulmonary disease. Am J Respir Crit Care Med. 2005;171(9):972-977.
5. Minakata Y, Sugino A, Kanda M, et al. Reduced level of physical activity in Japanese patients with chronic obstructive pulmonary disease. Respir Investig. 2014;52(1):41-48.

6. Waschki B, Kirsten A, Holz O, et al. Physical activity is the strongest predictor of all-cause mortality in patients with COPD: a prospective cohort study. Chest. 2011;140(2):331-342.

7. Rabe KF, Hurd S, Anzueto A, et al; Global Initiative for Chronic Obstructive Lung Disease. Global strategy for the diagnosis, management, and prevention of chronic obstructive pulmonary disease: GOLD executive summary. Am J Respir Crit Care Med. 2007;176(6):532-555.

8. Donohue JF, Fogarty C, Lötvall J, et al; INHANCE Study Investigators. Once-daily bronchodilators for chronic obstructive pulmonary disease: indacaterol versus tiotropium. Am J Respir Crit Care Med. 2010;182(2):155-162.

9. Kinoshita M, Lee SH, Hang LW, et al; Indacaterol Asian COPD Study Investigators. Efficacy and safety of indacaterol 150 and $300 \mu \mathrm{g}$ in chronic obstructive pulmonary disease patients from six Asian areas including Japan: a 12-week, placebo-controlled study. Respirology. 2012;17(2):379-389.

10. To Y, Kinoshita M, Lee SH, et al. Assessing efficacy of indacaterol in moderate and severe COPD patients: a 12-week study in an Asian population. Respir Med. 2012;106(12):1715-1721.

11. Kornmann O, Dahl R, Centanni S, et al; INLIGHT-2 (Indacaterol Efficacy Evaluation Using 150- $\mu$ g Doses with COPD Patients) study investigators. Once-daily indacaterol versus twice-daily salmeterol for COPD: a placebo-controlled comparison. Eur Respir J. 2011;37(2):273-279.

12. Buhl R, Dunn LJ, Disdier C, et al; INTENSITY study investigators. Blinded 12-week comparison of once-daily indacaterol and tiotropium in COPD. Eur Respir J. 2011;38(4):797-803.

13. Beeh KM, Wagner F, Khindri S, Drollmann AF. Effect of indacaterol on dynamic lung hyperinflation and breathlessness in hyperinflated patients with COPD. COPD. 2011;8(5):340-345.

14. O'Donnell DE, Casaburi R, Vincken W, et al; INABLE 1 study group. Effect of indacaterol on exercise endurance and lung hyperinflation in COPD. Respir Med. 2011;105(7):1030-1036.

15. Watz H, Krippner F, Kirsten A, Magnussen H, Vogelmeier C. Indacaterol improves lung hyperinflation and physical activity in patients with moderate chronic obstructive pulmonary disease - a randomized, multicenter, double-blind, placebo-controlled study. BMC Pulm Med. 2014;14(1):158.

16. Hataji O, Naito M, Ito K, Watanabe F, Gabazza EC, Taguchi O. Indacaterol improves daily physical activity in patients with chronic obstructive pulmonary disease. Int J Chron Obstruct Pulmon Dis 2013;8:1-5.

17. Global Strategy for the Diagnosis, Management and Prevention of COPD, Global Initiative for Chronic Obstructive Lung Disease (GOLD) 2010. Available from: http://www.goldcopd.org/

18. Kumahara H, Schutz Y, Ayabe M, et al. The use of uniaxial accelerometry for the assessment of physical-activity-related energy expenditure: a validation study against whole-body indirect calorimetry. Br J Nutr. 2004;91:235-243.

19. Sugino A, Minakata Y, Kanda M, et al. Validation of a compact motion sensor for the measurement of physical activity in patients with chronic obstructive pulmonary disease. Respiration. 2012;83(4): 300-307.

20. Celli BR, MacNee W; ATS / ERS Task Force. Standards for the diagnosis and treatment of patients with COPD: a summary of ATS / ERS position paper. Eur Respir J. 2004;23(6):932-946.

21. Jones PW, Harding G, Berry P, Wiklund I, Chen WH, Kline Leidy N. Development and first validation of the COPD Assessment Test. Eur Respir J. 2009;34(3):648-654.

22. Tsuda T, Suematsu R, Kamohara K, et al. Development of the Japanese version of the COPD Assessment Test. Respir Investig. 2012;50(2):34-39.

23. Fukuhara S, Bito S, Green J, Hsiao A, Kurokawa K. Translation, adaptation, and validation of the SF-36 Health Survey for use in Japan. J Clin Epidemiol. 1998;51(11):1037-1044. 
24. Fukuhara S, Ware JE Jr, Kosinski M, Wada S, Gandek B. Psychometric and clinical tests of validity of the Japanese SF-36 Health Survey. J Clin Epidemiol. 1998;51(11):1045-1053.

25. Miller MR, Hankinson J, Brusasco V, et al. Standardisation of spirometry. Euro Respir J. 2005;26:319-338.

26. Tudor-LockeC, BurkettL, Reis JP, AinsworthBE, Macera CA, WilsonDK. How many days of pedometer monitoring predict weekly physical activity in adults? Prev Med. 2005;40(3):293-298.
27. Steele BG, Holt L, Belza B, Ferris S, Lakshminaryan S, Buchner DM. Quantitating physical activity in COPD using a triaxial accelerometer. Chest. 2000;117(5):1359-1367.

\section{Publish your work in this journal}

The International Journal of COPD is an international, peer-reviewed journal of therapeutics and pharmacology focusing on concise rapid reporting of clinical studies and reviews in COPD. Special focus is given to the pathophysiological processes underlying the disease, intervention programs, patient focused education, and self management protocols.

\section{Dovepress}

This journal is indexed on PubMed Central, MedLine and CAS. The manuscript management system is completely online and includes a very quick and fair peer-review system, which is all easy to use. Visit $\mathrm{http}: / / \mathrm{www}$.dovepress.com/testimonials.php to read real quotes from published authors.

\footnotetext{
Submit your manuscript here: http://www.dovepress.com/international-journal-of-chronic-obstructive-pulmonary-disease-journal
} 